\title{
The Effects of a Pneumatic-Driven Variable Valve Timing Mechanism on the Performance of an Otto Engine
}

\author{
Fatih Uysal* - Selami Sagiroglu \\ Karabuk University, Faculty of Engineering, Turkey
}

In this study, the classic cam mechanism of a single cylinder, four-stroke, $6 \mathrm{hp}$ spark-ignited engine was replaced by an electro-pneumatic rocker mechanism, which is designed and manufactured to open the intake valve at low (3.7 mm), normal (5.7 mm) and high (7.7 mm) lifts between engine speeds of $1600 \mathrm{rpm}$ to $2200 \mathrm{rpm}$. An air compressor was used to feed 6 bar air pressure in order to have the plungers drive the cams in an orderly manner. A control panel was used to control plungers in order to modulate the valve lifts gradually. The volumetric efficiency, torque, power and specific fuel consumption with this operation were measured at full load and compared to the values with a classic cam mechanism. The results of the study showed that decreasing the valve lift at low engine speeds and increasing the lift at high speeds improve the engine performance. Moreover, it was concluded that the idle speed can be lowered by decreasing the valve lift at low engine speeds.

Keywords: variable valve timing (VVT), valve timing and lift electronic control system (VTEC), Otto engine, engine performance, spark ignition, electro-pneumatic rocker mechanism

\footnotetext{
Highlights

- The effects of a pneumatic-driven valve mechanism on the performance a designed and manufactured engine is investigated.

- $\quad$ The existing rocker system was bypassed, and exhaust and intake rockers were remanufactured in accordance with the reference engine. Idle rockers were manufactured for both sides of the intake rocker. Two pneumatic-driven plungers were designed and manufactured, which lock and unlock the idle rockers to the intake rocker according to their order.

- The obtained values indicate that, depending on the engine speed, valve lifting at different heights has a positive impact on the performance of the engine.

- $\quad$ The reduction of valve lift makes the start-up of the engine easier and ensures that the engine can be started with less electricity.
}

\section{INTRODUCTION}

Factors such as fuel economy, time economy, social concerns about environmental pollution and a production philosophy formed according to customer satisfaction, and the tightening of emission standard values by governments have forced designers to correct exhaust emissions accordingly and improve cam mechanisms. Particularly in the United States and Europe, the tightening of emission standard values and aggressive competitive conditions have forced automobile companies and universities to conduct research and development activities on cam mechanisms. Studies concentrate on the opening/ closing times of intake and exhaust valves, as any failure in joining the fuel atoms with oxygen atoms in combustion chambers deteriorates the quality of combustion and, consequently, causes the emission of carcinogenic materials from the exhaust, which are hazardous to human health; these include nitrogen oxides (NOx), carbon monoxide (CO), unburnt hydrocarbons (HC), etc.

In internal combustion engines, volumetric efficiency is the most important parameter affecting combustion performance. The other parameters are engine torque, power output, fuel economy, and exhaust emission. At all engine speeds, increasing the amount of charge taken into the cylinders, which means an improved volumetric efficiency by variable valve timing, will also affect other parameters positively.

Volumetric efficiency is affected by several factors: atmospheric conditions outside the engine, and thermodynamic conditions inside the engine, such as cylindrical volume, flow area of fuel-air mixture, engine speed, open-close timing of intake and exhaust valves and valve lifting (opening) level, pressure changes inside the cylinder, and others.

The intake of fresh charge into the cylinder and the expelling of burnt mixture in spark-ignited (SI) engines are performed by opening and closing of valves which are opened by a crankshaft driven camshaft. The timing of the opening and closing of valves is a function of the shape of the camshaft and position of the crankshaft. In classic cam mechanisms, the intake valve opens $12 \mathrm{deg}$ before it reaches top dead centre (TDC) and closes 56 deg after bottom dead centre (BDC). This provides additional time for taking more air-fuel mixture inside the cylinder [1]. This application can cause ideal results for an engine 
which works at fixed speed. Depending on the needs of car drivers, it can be used at low speeds in urban areas at first start-up and high speed in rural areas or places which requires high performance. It must be taken into consideration that classical valve timing is optimized for a certain speed and engine load, but in studies over or under this speed, volumetric efficiency decreases. Changing the opening and closing advances of the intake and exhaust valves affects the efficiency of the engine, depending on its working rotation and load status. Increasing the advance of intake valves increases the volumetric efficiency at medium and low engine speeds. In addition, volumetric efficiency decreases with decreased intake valve opening advance and decreased exhaust valve closing delay [2].

Recently, the need for fuel economy and further reductions of hazardous exhaust emissions has forced engine designers to alter classic valve mechanisms and seek alternative ones. As a result of research activities, several camshaft and valve mechanisms have been developed. The fundamental principle in these mechanisms is the same and widely used on vehicles today. Electromagnetic, electromechanical, electrohydraulic, electro-pneumatic valve mechanisms suffer from some problems; research in this area is ongoing [3].

At low engine speeds, intake and exhaust camshafts are taken to advance together; at high engine speeds the intake camshaft or both camshafts are delayed; thus, volumetric efficiency is improved [4]. In a variable valve timing system used by Ferrari, there are separate camshafts for both intake and exhaust valves. A helical gear is opened on the camshaft with intake valves and the shaft is moved at axial direction according to engine rotation; thus opening advances and closing delays of intake cams are thus altered [5]. The movement of the crankshaft is transmitted to the camshaft through a sprocket or timing belt pulley. Gradual alteration of the calibration of the tensioning system of the sprocket can change the advance of the camshaft. The advance alteration systems performed this way can also increase the efficiency of the engine [6]. According to the data received from the engine control unit, the solenoid valve directs engine hydraulic to a hydraulic cylinder; therefore, it can ensure that the cylinder moves the pallet and the camshaft can perform thus relative action independent of regular rotation movement, and the opening and closing advances of the valves are changed [7].

The opening amounts of the intake and exhaust valves also affect engine efficiency, depending on the engine speed and engine load status. Camshaft profiles are used in order to change the opening levels of valves. Mechanical, electrical, hydraulic, pneumatic, and other energy sources are used to engage and disengage different cam profiles. Usually, next to a central cam profile, there are other cam profiles that engage and disengage with the help of a feeder needle. The Honda variable valve timing and lift electronic control system (VTEC) is the first system in the world that can simultaneously switch the timing and lift of the intake and exhaust valves. This system has made improvements in the maximum output at high rpm and also improved the low rpm range, with regards to idling stability and starting capability [8]. The customization of valve lifts and open/close advances according to engine speeds increase engine efficiency [9]. With a two-graded Variable Valve Actuation system, which is lower than the regular profile of camshaft, a $6.9 \%$ decrease in fuel consumption can be achieved in dynamometer tests [10]. In such systems, which perform gradual variable valve timing and valve lift alteration, engine efficiency is optimum at several engine speeds instead of a single speed. Although it seems like a disadvantage, the low number of parts and low level of friction forces make these systems more utilizable.

Different systems of camshaft and its shape are being developed in order to open valves at different intake advances and close at closing advances. When the position of hall-effected sensors is changed to alter the advance of the valves in an electromagnetic valve mechanism fed by $42 \mathrm{~V}$ voltage, volumetric efficiency decreased and the air-fuel ratio deteriorated due to the bouncing of the intake valve disk, and the opening and closing delays at especially high engine speeds [3]. Appropriate systems have been developed for internal combustion engines, consisting of a planetary gear set, a worm mechanism, and a control motor that can continuously control the valve timing and lift [11]. As this type of system is being developed, its relation with existing systems also has to be examined. With a VVT strategy, a $5 \%$ to $6 \%$ improvement was observed in specific fuel consumption and a $47 \%$ decrease was achieved in pumping losses compared to the classic cam mechanism; in addition, a decrease was observed in NOX values without any decrease in combustion quality with EGR (exhaust gas recirculation) [12].

As a result, it is difficult to obtain the necessary change in the closing of intake valve; late closing is more appropriate in cases where the change in timing is minor [13]. Difficulties in variable valve timing, the fact that the resulting increase in efficiency is higher than the energy needed to drive the developed system, 
the low number of parts used, the long service life of the system, its failure-proof quality, and other factors have cause several methods to be researched for system development, although very few of them have become commercialized. For this reason, researches on the system is ongoing.

The purpose of this study is to investigate the design, manufacturing and effects of a pneumaticdriven valve mechanism on performance, which is similar to the VTEC model that drives the low and high cam noses with an unchanged profile at low and high rotations in addition to the classic cam nose on the same camshaft.

The design is based on the average speed of an engine with a classic cam mechanism in order to the optimize volumetric efficiency and air-fuel ratio. Pumping losses increase at low engine speeds, and the desired amount of charge cannot be taken into the cylinders at high rotation levels, due to the fixed cam mechanism, which results in a decreasing torque curve. In order to prevent such problems and achieve a horizontal torque curve, valves should open less at low engine speeds and more at high speeds. That is why variable valve timing is required.

\section{MATERIAL AND METHOD}

During the experiments two LONCIN brand, G200F(D) model four-stroke, single-cylinder, electronic ignition, $6 \mathrm{HP}$, gasoline engines and a KEMSAN brand $10 \mathrm{~kW}$ dynamometer were used. In Table 1, the technical specifications of the reference and testing machines are given.

Table 1. Technical features of testing engine

\begin{tabular}{lc}
\hline Brand & LONCIN BRAND 4 stroke, gasoline \\
\hline Model & G200F(D) \\
\hline Number of cylinders & 1 \\
\hline Piston stroke & $54 \mathrm{~mm}$ \\
\hline Cylinder diameter & $68 \mathrm{~mm}$ \\
\hline displacement & $196 \mathrm{~cm}^{3}$ \\
\hline Ignition & Electronic ignition \\
\hline Classical cam intake valve lift & $5.7 \mathrm{~mm}$ \\
\hline Intake valve low lift & $3.7 \mathrm{~mm}$ \\
\hline Intake valve high lift & $7.7 \mathrm{~mm}$ \\
\hline
\end{tabular}

The first engine is the "reference engine" (classic cam mechanism engine), and the second engine is "test engine" (variable valve mechanism engine). Some modifications were made in the test engine:

1. In the reference engine, the crank and camshaft gears were directly connected to each other, whereas in the test engine the camshaft and crankshaft are connected with a timing belt (Fig. 1). Theintake and exhaust cams on the camshaft were remanufactured. In addition, $2 \mathrm{~mm}$ low and $2 \mathrm{~mm}$ high cams were added next to the regular intake cam.

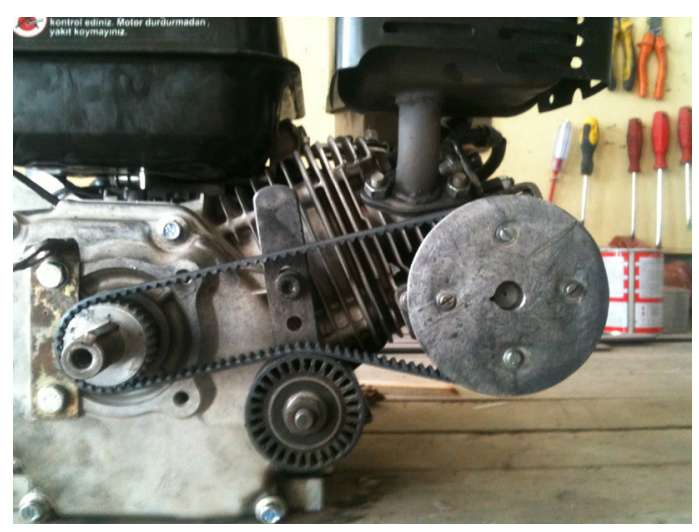

Fig. 1. Test engine

2. The existing rocker system was bypassed, and exhaust (A) and intake rockers (B) were remanufactured in accordance with the reference engine. Idle rockers $(\mathrm{C})$ were manufactured at both sides of the intake rocker. Two pneumatic driven plungers (D) were designed and manufactured, which lock and unlock the idle rockers to the intake rocker according to their order (Fig. 2).

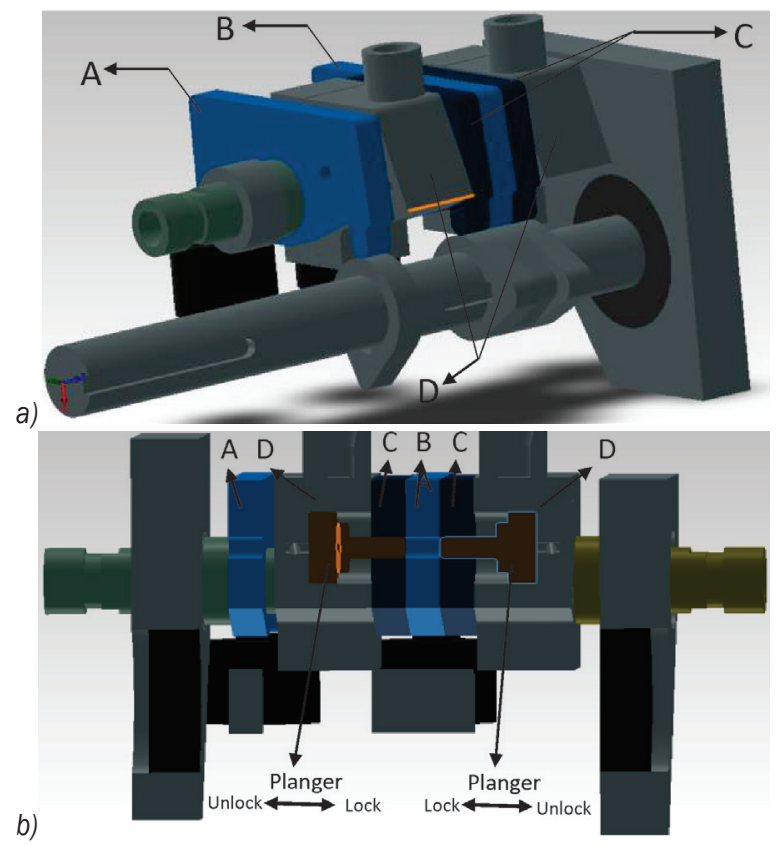

Fig. 2. a) New camshaft and rocker system; b) idle rocker plunger cross-sections 
3. A quick coupler (E) was mounted at the end of rocker rod to feed air for pneumatic driven plunger system. Due to this coupler rocker, a carburettor was taken $30 \mathrm{~mm}$ away from the intake manifold using an intermediate connecting part (F) (Fig. 3).

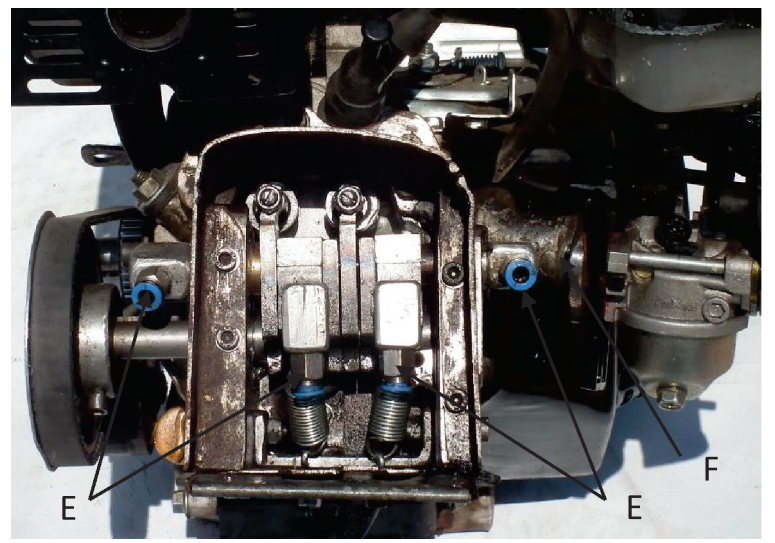

Fig. 3. The connecting part between intake manifold and the carburettor

4. A control panel was manufactured so that the plungers could step in and out at desired engine speeds. The air required by the system was provided by an external compressor and electricity was used from the mains $\left(220 \mathrm{~V}_{\mathrm{AC}}\right)$ (Figs. 4 and 5).

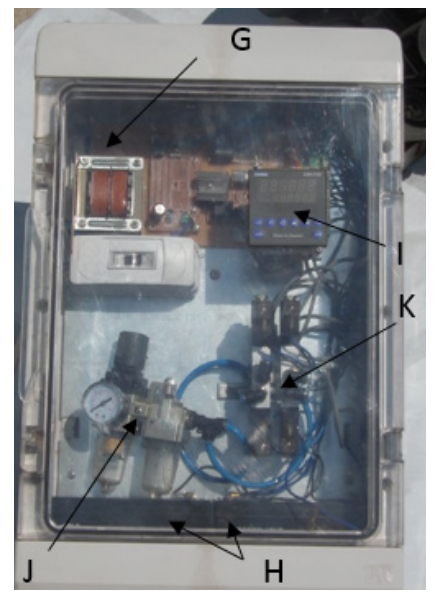

Fig. 4. Control panel

A $220 \mathrm{~V}_{\mathrm{AC}}$ to $12 \mathrm{~V}_{\mathrm{DC}}$ supply unit (G), two 12 $\mathrm{V}_{\mathrm{DC}}, 7 \mathrm{Ah}$ batteries $(\mathrm{H})$, a double-contact tachometer (I), a conditioner $(\mathrm{J})$, and a $5 / 3$ electro pneumatic valve $(\mathrm{K})$ were used so that this panel does not cause delay during operation (Fig. 4). The SET value on the tachometer can be adjusted to define at which engine speeds the system will engage and disengage the low and high cams. The data-reading speed of the tachometer can also be adjusted to prevent the evaluation of instant changes in engine speed in order to provide unnecessary fluctuation of engagement and disengagement. The electricity needed to operate the panel was supplied by two batteries in addition to the engine, since the supply voltages of circuit elements are different $\left(12\right.$ or $\left.24 \mathrm{~V}_{\mathrm{DC}}\right)$.

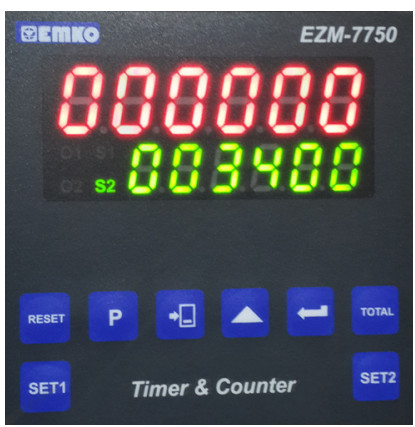

Fig. 5. Tachometer on control panel

The testing mechanism is shown in Fig. 6.

1. Dynamometer

2. Coupler

3. Test engine

4. Conditioner

5. Air tank

6. Compressor

7. $5 / 3$ electro pneumatic valve

8. Plunger (single impact spring return)

9. Tachometer (double-contact, normally open, normally closed)

10. 2 batteries (12 Vdc, $7 \mathrm{Ah})$

11. Proximity switch

For the measurements, the engine was brought to operating temperature, the throttle was blocked fully open, and the engine was loaded with a dynamometer. The engine was tested by increasing the engine speed from $2000 \mathrm{rpm}$ to $4000 \mathrm{rpm}$ at 6 steps with $400 \mathrm{rpm}$ increments.

\subsection{Method}

In order to adjust the valve lift in the test engine, the set values of the tachometer on the control panel were adjusted. For the normal cam, the SET1 ON value was set to $2300 \mathrm{rpm}$, the SET1 OFF value was set to 2200 rpm; for the high cam, the SET2 ON value was set to $3300 \mathrm{rpm}$, and the SET2 OFF value was set to 3200 $\mathrm{rpm}$. Thus, it was ensured that during the acceleration, low, normal and high cams operated at $0 \mathrm{rpm}$ to $2300 \mathrm{rpm}, 2300 \mathrm{rpm}$ to $3300 \mathrm{rpm}$ and $3300 \mathrm{rpm}$ to $5500 \mathrm{rpm}$ ranges, respectively. When the engine is 


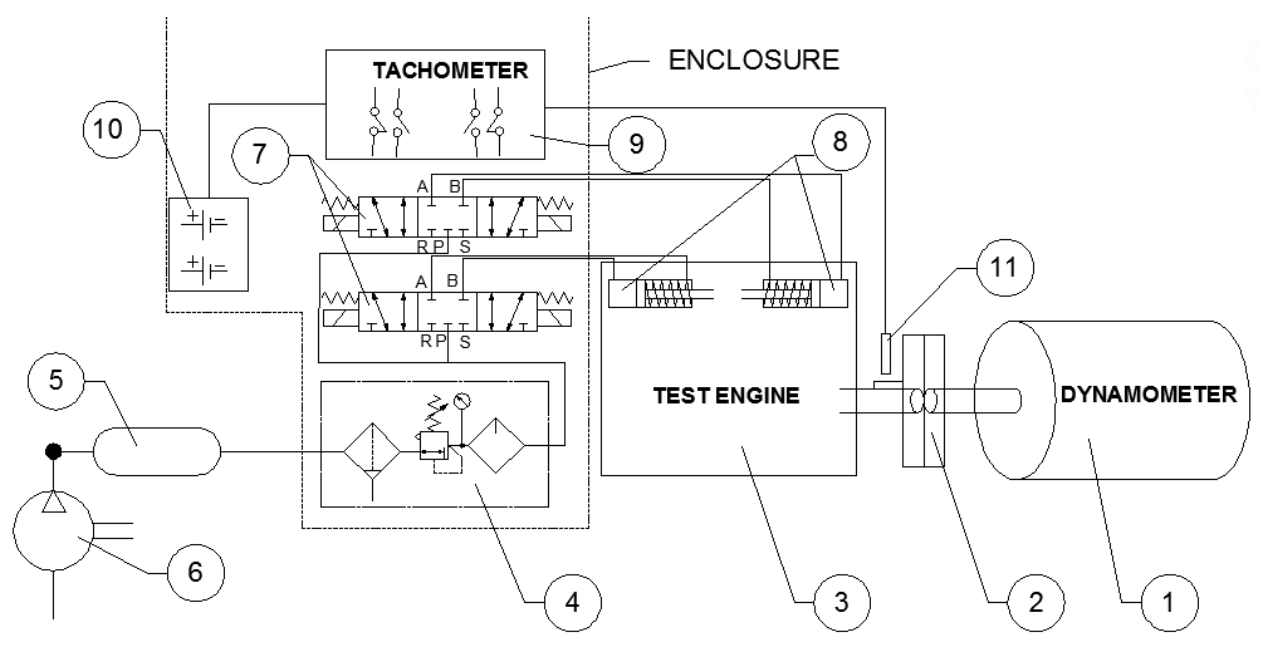

Fig. 6. Experimental setup

decelerating, low, normal and high cams operate at below $2200 \mathrm{rpm}, 2200 \mathrm{rpm}$ to $3200 \mathrm{rpm}$ and 3200 rpm to $5500 \mathrm{rpm}$ ranges, respectively. Different limits between acceleration and deceleration courses did not affect the test results as they did not correspond to the measurement speeds. The purpose of adjusting different on/off values is to prevent damage caused on the variable timing valve control system by frequent engagement and disengagement due to minor engine rotation changes and to ensure that the system has a longer life.

Before the tests were started, the engine was operated at idle for 15 minutes so that the operation temperature could be reached. Then the throttle was brought to the fully open position, the engine was loaded with a dynamometer, and measurements were taken.

Tests were conducted at $1600 \mathrm{rpm}$ to $4000 \mathrm{rpm}$ interval with $400 \mathrm{rpm}$ speed increments. Intake valve lift data was taken at all speeds; $2000 \mathrm{rpm}, 2800 \mathrm{rpm}$ and $4000 \mathrm{rpm}$ engine speeds were chosen for low cam, classical cam and high cam, respectively, in order to compare engine performance as they were very stable operating speeds for those cam types.

\subsubsection{Effective Moment and Power of the Engine}

When the engine is operated at the abovementioned speeds, the force value was read from the dynamometer indicator. The force value for each speed (kgf: kilogram-force) was multiplied with the dynamometer moment arm length $(0.25 \mathrm{~m})$ and the effective moment at that speed was found [14] and [15].

$$
M_{e}=F \times l \times 9.81 \text {. }
$$

The effective power of the engine is calculated by using Eq. (2) [14] and [15]:

$$
N_{e}=\frac{M_{e} \times n}{9549.3} .
$$

\subsubsection{Measuring Fuel Consumption and Calculation of Specific Fuel Consumption}

Super gasoline was used as test fuel. Under testing conditions, a chronometer was used to measure the time depletion time of $15 \mathrm{ml}$ fuel in the fuel measurement tube under test conditions, and fuel consumption was calculated.

The specific fuel consumption is calculated using Eq. (3) [14] and [15].

$$
b_{e}=\frac{B_{y}}{N_{e}} \times 1000 .
$$

\subsubsection{Air Consumption and Volumetric Efficiency}

For air consumption, an air orifice diameter suitable for the engine was calculated first and the orifice shown in Fig. 7 was used.

In the test orifice diameter $(d)$ was applied as 18 $\mathrm{mm}$ and pressure $(h)$ was taken from the manometer as " $m m \mathrm{H}_{2} \mathrm{O}$ column". Real air consumption was calculated as [14].

$$
Q_{\text {real }}=0.1123 \times d^{2} \times \sqrt{h} .
$$


The density of dry air at sea level under standard atmospheric pressure and $15^{\circ} \mathrm{C}$ was taken as 1.225 $\mathrm{kg} / \mathrm{m}^{3}$.

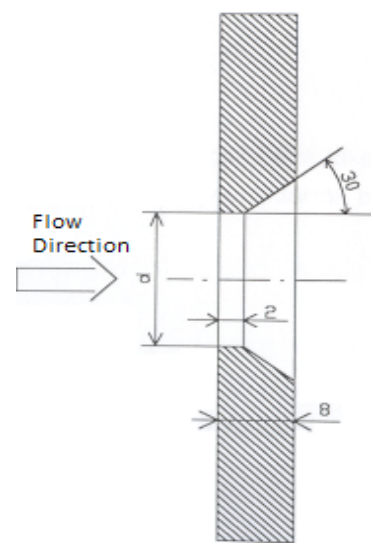

Fig. 7. Airflow orifice

Volumetric efficiency is calculated as a percentage by dividing the real air consumption $\left(Q_{\text {real }}\right)$ for every speed with the amount of air $\left(Q_{\text {theoretical }}\right)$ that the engine theoretically has to consume at that speed [15].

$$
\eta_{v}=\frac{Q_{\text {real }}}{Q_{\text {theoretical }}} .
$$

Here, theoretical air consumption is calculated according to displaced cylinder volume $\left(V_{h}\right)$ [15] with Eq. (6):

$$
Q_{\text {theoretical }}=V_{h} \times \frac{n}{2} \text {. }
$$

\subsubsection{Excess Air Coefficient $(\lambda)$}

Stoichiometric (or chemically correct or theoretical) proportions of fuel and air can be defined as the existence of just enough oxygen for conversion of all the fuel into completely oxidized products $(\lambda=1)$ [15].

An MRU DELTA 1600L exhaust gas analysis device was used to measure exhaust emissions and the ambient temperature. The device calibrates itself in 15 minutes at start up. The exhaust-measuring probe of the engine analyser is installed into the exhaust pipe of the engine. After the engine was brought to normal working conditions, excess air coefficient, exhaust emissions and ambient temperature values were measured at the given engine speeds.

\section{EVALUATION OF TEST RESULTS}

Tests were conducted at $1600 \mathrm{rpm}$ to $4000 \mathrm{rpm}$ range with $400 \mathrm{rpm}$ increments. Intake valve lift data was taken at all speeds and $2000 \mathrm{rpm}, 2800 \mathrm{rpm}$ and 4000 $\mathrm{rpm}$ engine speeds were chosen as reference speeds for low cam, classic cam and high cam, respectively, in order to compare engine performance, as they were very stable operation speeds for those cam types.

\subsection{Volumetric Efficiency}

It can be seen from Fig. 8 that at 2000 rpm the highest volumetric efficiency was measured at the low cam situation of the test engine with $60.86 \%$; at the same speed, the volumetric efficiency of the reference engine was measured as $44.51 \%$, meaning a $16.35 \%$ increase in volumetric efficiency of the test engine. At $2800 \mathrm{rpm}$, the highest volumetric efficiency was measured at the classic cam situation of test engine with $52.20 \%$; at the same speed, the volumetric efficiency of the reference engine was measured as $50.05 \%$, which means a $2.15 \%$ increase in the volumetric efficiency of the test engine. At $4000 \mathrm{rpm}$, the highest volumetric efficiency was measured at the high cam situation of test engine with $38.55 \%$; at the same speed, the volumetric efficiency of the reference engine was measured as $35.19 \%$, meaning a $3.36 \%$ increase in the volumetric efficiency of the test engine.

The reason the test engine gives the highest volumetric efficiency in the low cam situation at 2000 rpm is that, depending on the decrease of the valve lift, pumping losses decrease, the flow speed of the fuel-air mixture passing through the valve opening increases, as a result of which turbulence inside the cylinder increases and the fuel-air mixture becomes more homogeneous.

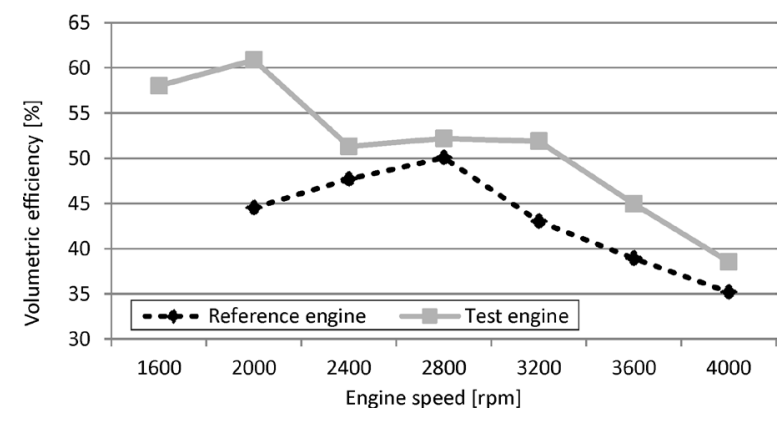

Fig. 8. Impact of intake valve lifts on volumetric efficiency according to the engine speed

The reason the test engine gives almost the same volumetric efficiency in a classic cam situation at $2800 \mathrm{rpm}$ is that they have identical cams. As the classic cam of the test engine is remanufactured, a $2.15 \%$ increase was witnessed in efficiency due to differences attributable to manufacturing and 
installation. The reason that the test engine generates higher volumetric efficiency at high cam situation at $4000 \mathrm{rpm}$ is that, although the open period of the valve at high speed decreased, the valve lift increased, which reduced the flow speed of the fuel-air mixture into the cylinder and increased the vacuum by the downward movement of the piston. Therefore, the volumetric efficiency increases.

\subsection{Excess Air Coefficient $(\lambda)$}

When the excess air coefficient graph is examined (Fig. 9), it shows that at $2000 \mathrm{rpm}$ engine speed, when test engine is at low cam status, $\lambda$ was measured as 1.048 , whereas the $\lambda$ of the reference engine in the same speed was measured as 1.111 . The test engine remained in the lean mixture side with a $4.8 \%$ deviation and stayed the closest to the ideal value. At a $2800 \mathrm{rpm}$ engine speed, when the test engine is at classic cam status, $\lambda$ was measured as 0.978 , whereas the $\lambda$ of the reference engine in the same speed was measured as 0.995 . The test engine remained in the rich mixture side with a $2.2 \%$ deviation, and the reference engine remained in the rich mixture side with a $0.5 \%$ deviation. At a $4000 \mathrm{rpm}$ engine speed, when $\lambda$ of test engine was measured as 0.842 at high cam status, the $\lambda$ of the reference engine in the same speed was measured as 1.072 , and the test engine remained in the lean mixture side with a $15.8 \%$ deviation.

The excess air coefficient $(\lambda)$ approached the ideal value at low cam but moved away from it at high cam to the rich mixture side.

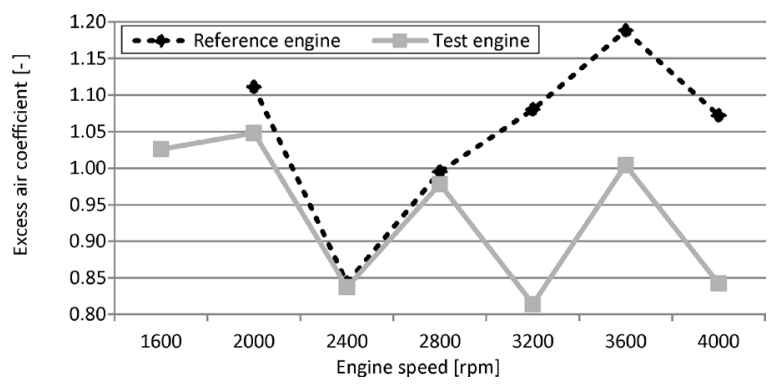

Fig. 9. Impact of intake valve lifts on $\lambda$ according to the engine speed

This was partly the result of the carburettor design, which was made for the classic cam system and its detachment from intake manifold with a connecting piece. This system is more suitable for fuel injection systems.

\subsection{Moment}

The moment of the test engine (Fig. 10) at $2000 \mathrm{rpm}$ speed at low cam status was measured as $10.3 \mathrm{Nm}$, whereas the moment of the reference engine at the same speed was measured as $9.31 \mathrm{Nm}$, meaning a $10.63 \%$ increase in the moment of the test engine compared to the reference engine. The moment of the test engine at $2800 \mathrm{rpm}$ speed at classic cam status was measured as $12.75 \mathrm{Nm}$, whereas the moment of the reference engine at the same speed was measured as $12.51 \mathrm{Nm}$, meaning a $1.92 \%$ increase in the moment of the test engine compared to the reference engine. The moment of the test engine at $4000 \mathrm{rpm}$ speed at high cam status was measured as $11.53 \mathrm{Nm}$, whereas the moment of the reference engine at the same speed was measured as $8.83 \mathrm{Nm}$, meaning a $30.58 \%$ increase in the moment of the test engine compared to the reference engine.

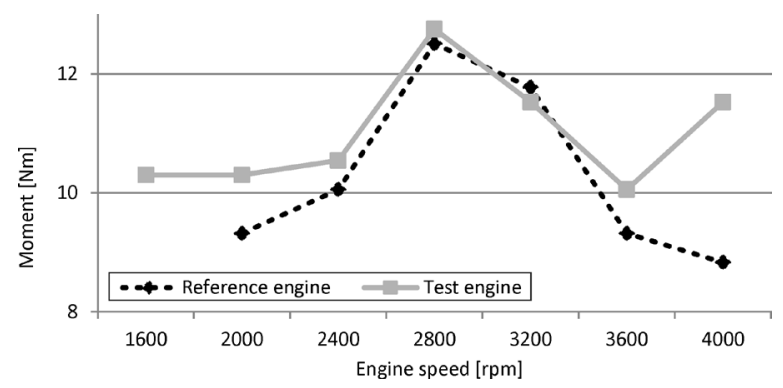

Fig. 10. The impact of the different intake valve lifts on the engine moment according to the engine speed

At $2000 \mathrm{rpm}$, the reason for the moment increase in test engine at low cam status is that the fuel-air mixture taken inside the cylinder increased depending on the increase in volumetric efficiency, and that $\lambda$ took an almost ideal value (1.048). At $2800 \mathrm{rpm}$, the reason for which the test engine gave almost the same moment in classic cam status is that the cams are almost identical. As the classic cam of the test engine was remanufactured, due to differences caused by manufacturing and installation, a $1.92 \%$ increase was observed in efficiency. The reason for the moment increase at high cam situation at $4000 \mathrm{rpm}$ speed is the increase in volumetric efficiency and that $\lambda$ remained in the side of the rich mixture.

\subsection{Engine Power}

When Fig. 11 is examined, at $2000 \mathrm{rpm}$ engine, and the test engine at low cam status, the power of the engine was measured as $2.16 \mathrm{~kW}$; meaning a $10.77 \%$ increase in test engine compared to the reference 
engine. At $2800 \mathrm{rpm}$, and the test engine at classic cam status, engine power was measured as $3.74 \mathrm{~kW}$; compared to the $3.67 \mathrm{~kW}$ power of the reference engine at the same speed, meaning a $1.91 \%$ increase in the power of the test engine. At $4000 \mathrm{rpm}$, and test engine at high cam status, the engine power was measured as $4.83 \mathrm{~kW}$, whereas the power of reference engine at the same speed was measured as $3.70 \mathrm{~kW}$, meaning a $30.54 \%$ increase in the power of the test engine.

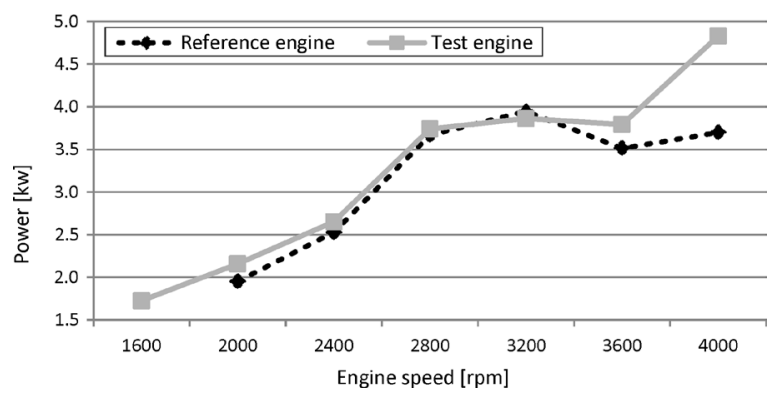

Fig. 11. The impact of the different intake valve lifts on the engine power according to the engine speed

As engine power is a function of its moment and speed, at high engine speeds work production per unit time increased and so the engine power was measured more with increased moment at these speeds.

\subsection{Specific Fuel Consumption}

The specific fuel consumption of the test engine (Fig. 12) at $2000 \mathrm{rpm}$ at low cam status was measured as $427.85 \mathrm{~g} / \mathrm{kWh}$, whereas the specific fuel consumption of the reference engine was measured as $461.10 \mathrm{~g} / \mathrm{kWh}$, meaning a $7.2 \%$ decrease in the fuel consumption of test engine compared to that of reference engine. At $2800 \mathrm{rpm}$, the specific fuel consumption of the test engine at classic cam status was measured as 388.794 $\mathrm{g} / \mathrm{kWh}$, whereas the specific fuel consumption of the reference engine was measured as $399.34 \mathrm{~g} / \mathrm{kWh}$, meaning a $2.64 \%$ decrease in the fuel consumption of test engine compared to that of reference engine. At $4000 \mathrm{rpm}$, the specific fuel consumption of the test engine at high cam status was measured as $\mathbf{3 3 5 . 5 2}$ $\mathrm{g} / \mathrm{kWh}$, whereas the specific fuel consumption of the reference engine was measured as $425.87 \mathrm{~g} / \mathrm{kWh}$, meaning a $26.93 \%$ decrease in the fuel consumption of the test engine compared to that of the reference engine.

The reason for the decrease in the specific fuel consumption of test engine at low cam status at 2000 $\mathrm{rpm}$ speed is the increase in volumetric efficiency, with the fuel-air mixture being more homogeneous and the resulting in increase of moment and power values.

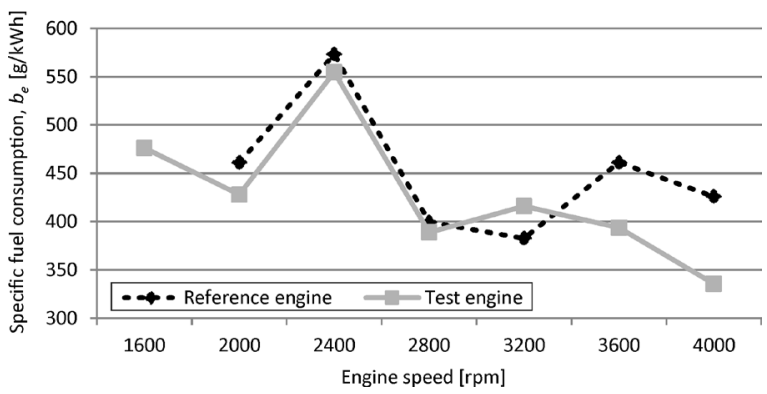

Fig. 12. The impact of the different intake valve lifts on the specific fuel consumption according to the engine speed

At $2800 \mathrm{rpm}$, the reason the test engine gave almost the same specific fuel consumption in the classic cam status is that the cams are almost identical. As the classic cam of the test engine was remanufactured, a $2.64 \%$ decrease was observed in fuel consumption due to differences caused by manufacturing and installation. At $4000 \mathrm{rpm}$, the reason the test engine showed less specific fuel consumption at high cam status of the test engine is the increase in volumetric efficiency and $\lambda$ remaining in the rich mixture side, as well as increased moment and power outputs.

\section{CONCLUSION AND RECOMMENDATIONS}

In these tests, the highest volumetric efficiency was found to be $60.86 \%$ at low cam at $2000 \mathrm{rpm}$; the most ideal $\lambda$ value was found to be 0.995 at classic cam at $2800 \mathrm{rpm}$; the highest increase in moment was found as $30.58 \%$ at high cam at $4000 \mathrm{rpm}$; the highest decrease in specific fuel consumption was observed as $30.54 \%$ at $4000 \mathrm{rpm}$. These obtained values indicate that, depending on the engine speed, valve lifting at different height has a positive impact on the performance of an engine.

During these tests, the idle speeds of the engines were also measured; when the idle of the classic cam engine decreased below $1200 \mathrm{rpm}$, the engine stopped; the test engine worked at $900 \mathrm{rpm}$ idle speed at low cam.

The improvements in engine performance at low cam will contribute to fuel economy, particularly for vehicles used in urban transportation.

The reduction of valve lift makes the start-up of the engine easier and ensures that the engine can be started with less electricity. An automatic stopstart module that will be installed in cars will ensure savings from electric energy when the engine is 
stopped and restarted at traffic lights. Thus, fuel economy can be achieved especially in roads with several and long traffic lights.

The fact that the engines used in the test had carburettors, and that the amount of fuel mixed with air depended on the structure of carburettor nozzle led to different $\lambda$ values at different speeds. Repeating similar tests with injection and semi-injection engines will display different results.

\section{REFERENCES}

[1] Crouse, W.H., Anglin, D.L. (1994). Automotive Engines, 8th ed. Macmillan/Mc Graw Hill, New York.

[2] Aslan, R., Sürmen, A., Avcl, A. (1997). Theoretical and experimental investigation of volumetric effects on valve timing in a diesel engine. $5^{\text {th }}$ Combustion Symposium, Bursa, p. 220-230.

[3] Sagiroglu, S., Salman, M.S. (2007). Design and manufacturing of an electromagnetic valve train and the effects on exhaust emissions in a spark ignition engine. Technology, vol. 10, no. 2, p. 113-122.

[4] Leone, T. Christenson, E., Stein, R., (1996). Comparison of variable camshaft timing strategies at part load. SAE Technical Paper, no. 960584, p. 664-674, D0l:10.4271/960584.

[5] Titolo, A. (1991). The variable valve timing system-application on a V8 engine. SAE Technical Paper, no. 91009, p. 7-11, DOl:10.4271/910009.

[6] Li, L., Su, Y., Wang, Y., Tao, J., Xiao, M. (2001). Development of an electrical control VVT system for high speed SI engines. Proceedings of the IEEE International Vehicle
Electronics Conference, Tottori, p. 115-119, D0l:10.1109/ IVEC.2001.961736.

[7] Knecth, A., Stephan, W., Hannibal, W. (2002). VaneCAM - The third generation of camshaft adjustment system. Motortechnische Zeitschrift Worldwide, vol. 63, no. 4, p. 1518.

[8] Hosaka, T., Hamazaki, M. (1991). Development of the variable valve timing and lift (VTEC) engine for the Honda NSX. SAE Technical Paper, no 910008, p. 1-6, D0I:10.4271/910008.

[9] Pierik, J.R., Burkhard, F.J. (2000). Design and development of a mechanical variable valve actuation system. SAE Technical Paper, no. 2000-01-1221, p. 1-8, D0I:10.4271/2000-01-1221.

[10] Sellnau, M., Kunz, T., Sinnamon, J., Burkhard, J. (2006). 2-Step variable valve actuation: System optimization and integration on an SI engine. SAE Technical Paper, no. 2006-01-0040, DOI:10.4271/2006-01-0040.

[11] Nagaya, K., Kobayashi, H., Koike, K. (2006). Valve timing and valve lift control mechanism for engines. Mechatronics, vol. 16, no. 2, p. 121-129, D0l:10.1016/j.mechatronics.2005.09.007.

[12] Fontana, G., Galloni, E. (2009). Variable valve timing for fuel economy improvement in a small spark-ignition engine. Applied Energy, vol. 86, no. 1, p. 96-105, D0l:10.1016/j. apenergy.2008.04.009.

[13] Stone, R., Kwan, E. (1989). Variable valve actuation mechanisms and the potential for their application. SAE Technical Paper, no. 890673, D0l:10.4271/890673.

[14] Martyr, A.J., Plint, M.A. (2007). Engine testing, 3rd ed. Elsevier, London, p. 144-146, p. 256-259, D0l:10.1016/B978075068439-2/50011-6.

[15] Heywood, J.B. (2000). Internal Combustion Engine Fundamentals, International edition. Mc-Graw Hill, Singapore, p. 46-55, p. 69-71. 